chapters deal with the assessment of respiratory function, endocrine function, the genetics and malformations, seizure disorders, diabetes in childhood and the nephrotic syndrome. Two whole chapters by Frommel and Good deal with immunological mechanisms and their associated disorders. However, much of their material is not strictly speaking confined to the paediatric age groups.

Although the individual chapters are written effectively it is inevitable that there are some inconsistencies of style but this is a small price to pay for authoritative material. It is perhaps in the choice of subjects and contributors that the greatest criticism must lie. It is difficult to apply the term 'recent' to much of the material since many of the topics have been extensively reviewed elsewhere and there would seem to be little new information that would warrant this description. It might also be thought that the book would have greater authority if all the contributors were active workers in the fields which they have reviewed. The reader is left with an overall impression that recent advances in this subject emanate from only a few centres in the United Kingdom and one in the United States and it is to be hoped that subsequent editions will enjoy a less parochial selection of authors.

Nevertheless, the book will be enjoyed by practising paediatricians as a review document for subjects with which they may not be actively involved and as an invaluable source of reference material. The production is satisfactory although for the quality of paper used, the book would seem to be somewhat overpriced.

\section{Surgical Treatment of Coronary Arteriosclerosis}

By Rene G. Favaloro. Introduction by Donald EfFler. Pp. $130+$ xvi, illustrated. Baltimore: Williams and Wilkins, 1970.

This monograph is based on the clinical experience with 2441 patients with coronary arteriosclerosis dealt with at the Cleveland Clinic between January, 1962 and December, $1968 \stackrel{0}{10}$
An interesting preface by D. B. Effler introduces the problem and outlines the evolution of this modern surgicale treatment. It is only after the clinical application of Sones's $\overline{3}$ technique in coronary angiography that it was possible to develop such surgical practice. Effler stresses that revasculariz- $c$ tion surgery of the heart begins and ends with arteriography The chapter on anatomy of the coronary arteries and its correlation with coronary cineangiography is very clear and excellently produced. The mortality rate of cinecoronarteriography and left cineventriculography in 13,602 patients was $\overline{\bar{\sigma}}$ $0.09 \%$. Valuable advice was given on the postoperative care $\frac{\bar{s}}{\sqrt{5}}$ of such patients.

Direct and indirect myocardial revascularization as well as associated ventricular aneurysmectomy and the complica- $\omega$ tions following surgery are clearly presented. More than $900 \rightarrow$ saphenous venous grafts had been performed up to $1970.0^{\circ}$ The mortality rate following such operation has fallen to $\vec{A}$ $2.3 \%$ even after cardiopulmonary bypass. The mortality rate following double Vineberg mammary artery implantation was 7.3\%. 191 patients were submitted to ventricularo aneurysmography with a mortality rate of $12 \%$.

The good results at such a famous centre were attributed $A$ to the careful selection of patients and the availability of well- $-\mathrm{V}$ equipped medical and surgical teams to deal with such prob-or lems. The surgical treatment of acute coronary insufficiency $\rightarrow$ although the results in many centres are not very encouraging, $\infty$ the author believes that such patients should be admitted $A$ under the direction of a combined surgical and medical team.을 $\mathrm{He}$ also advocates emergency angiography and surgich intervention. Management of acute coronary ischenis surgically is a recent procedure and new developments sure to take place in the near future.

This is an excellent monograph, full of important material which must interest cardiologists and cardiac surgeon. Post graduates will find it one of the best monographs available dealing with such problems. 